\title{
Jaringan Komputer Berbasis Radius Server untuk Meningkatkan Pemanfaatan Internet di Madrasah Aliyah Al-Azhaar Ummu Suwanah
}

\author{
Fadlan Abdillah Hasibuan ${ }^{1}$, Subhiyanto ${ }^{2}$
}

\begin{abstract}
This research aims to create a proxy hotspot network to connect to the internet with a login system for users, namely teachers, staff and students at Madrasah Aliyah Al-Azhaar Ummu Suwanah and create a user management system on the hotspot so that network administrators can control and monitor users. and network security can be covered. Building a mikrotik hotspot network at Madrasah Aliyah Al-Azhaar Ummu Suwanah with the PIECES modeling analysis method using Winbox, while for network development with Usermanager. The test results conducted by the user have been connected to the proxy hotspot and got the bandwidth according to the package received. The design of the proxy hotspot network at Madrasah Aliyah Al-Azhaar Ummu Suwanah shows that the proxy hotspot provides convenience and practicality in using the internet.
\end{abstract}

Intisari- Penilitian ini bertujuan untuk membuat sebuah jaringan hotspot mikrotik agar terhubung ke internet dengan sistem login untuk para pengguna yaitu, guru, staff maupun siswa di Madrasah Aliyah Al-Azhaar Ummu Suwanah dan membuat sebuah sistem manajemen user pada hotspot sehingga administrator jaringan dapat mengontrol dan memonitoring user serta keamanan jaringan bisa tertutupi. Membangun jaringan hotspot mikrotik di Madrasah Aliyah Al-Azhaar Ummu Suwanah dengan metode analisis pemodelan PIECES menggunakan winbox, sedangkan untuk pengembangan jaringan dengan usermanager. Hasil uji coba yang dilakukan pengguna sudah terhubung ke hotspot mikrotik dan mendapat bandwidth sesuai dengan paket yang didapat. Rancang bangun jaringan hotspot mikrotik di Madrasah Aliyah Al-Azhaar Ummu Suwanah ini menunjukkan bahwa hotspot mikrotik memberikan kemudahan dan kepraktisan dalam penggunaan internet.

Kata Kunci-Hotspot Mikrotik, Manajemen User, Usermanager, RADIUS Server.

\section{PENDAHULUAN}

Penggunaan internet saat ini menjadi kebutuhan yang cukup penting dalam segala bidang dan salah satunya dalam bidang pendidikan seperti di sekolah. Penggunaan internet dilingkungan sekolah tidak hanya dilakukan oleh guru dan karyawan, tetapi juga oleh para siswa.

Internet digunakan untuk berselencar mencari informasi, mencari sumber belajar lainnya, atau untuk sistem informasi di sekolah. Internet dapat diartikan sebagai kumpulan beberapa komputer atau jutaan komputer di seluruh dunia yang saling terkoneksi melalui media kabel/ serat optic, satelit atau melalui sambungan telepon. Salah satu yang sering

\footnotetext{
${ }^{1,2}$ Jurusan Teknik Informatika, STMIK Antar Bangsa, Jl. HOS Cokroaminoto, Kawasan Bisnis CBD Ciledug, Blok A5 No 29-36, Karang Tengah, Tangerang 15157, tlp: 021-50986099; e-mail: fadlanabdillahhasibuan@gmail.com, subhivanto@antarbangsa. ac.id
}

disediakan bagi pengguna internet adalah hotspot. Hotspot itu sendiri adalah suatu tempat yang memiliki layanan internet dengan menggunakan teknologi Wireless LAN yang dapat diakses melalui notebook atau perangkat lainnya [1].

Madrasah Aliyah Al-Azhaar Ummu Suwanah merupakan salah satu Madrasah Aliyah yang berada di jalan KH. Hasyim Ashari / Al-Furqon Gg. Wakaf RT.003/003 Poris Plawad Kecamatan Cipondoh Kota Tangerang. Saat ini Madrasah Aliyah Al-Azhaar Ummu Suwanah memiliki jaringan komputer berupa Wireless Local Area Network (WLAN) yang menggunakan koneksi internet dari modem andromax dan digunakan oleh 8 laptop dan perangkat lainnya seperti handphone. Dengan mengandalkan sumber internet dari modem andormax tersebut akan mempengaruhi performa koneksi internet atau lambatnya koneksi akses untuk internet bagi pengguna baik guru, staff maupun siswanya tanpa ada manajemen bandwidth. Kemudian 8 laptop dan pengguna jaringan wireless lainnya untuk guru, staff dan siswa tersebut tidak menggunakan pengamanan atau username dan password, belum adanya konfigurasi user dengan profile yang berbeda yang menyebabkan koneksi internet tidak stabil serta belum adanya manajamen user sebagai administrator jaringan komputer untuk hotspot.

Dari permasalahan diatas maka penulis tertarik untuk melakukan perancangan jaringan hotspot menggunakan mikrotik dengan sistem login pada jaringan komputer madrasah sebagai salah satu sistem untuk memudahkan client atau pengguna dalam pengkoneksian akses untuk internet, manajemen bandwidth untuk setiap pengguna dan untuk keamanan jaringan itu sendiri. Selain sistem login untuk pengguna hotspot, perancangan jaringan hotspot menggunakan mikrotik ini juga merancang untuk administrator jaringan sebagai mengelolah semua kebutuhan jaringan komputer untuk hotspot. Oleh karena itu, penulis melakukan penelitian dengan judul "Jaringan Komputer Berbasis RADIUS Server pada Madrasah Aliyah Al-Azhaar Ummu Suwanah Untuk Meningkatkan Pemanfaatan Internet”.

Mikrotik merupakan sistem operasi router, yang di rilase dengan nama mikrotik router OS yang mampu di install pada komputer biasa, tidak seperti sistem operasi router lainnya yang hanya bisa di install pada hardware tertentu. Mikrotik memiliki filtur yang diantarannya: Fireweall dan NAT, routing, hotspot, point to point tunneling protocol, DNS server, DHCP server, manajemen bandwidth, konfigurasi keamanan dan masih banyak filtur lainnya [2].

Penulis membatasi permasalahan hanya pada jaringan komputer, mulai dari konfigurasi hotspot mikrotik, membuat login hotspot untuk pengguna, dan manajemen user serta mengatur kapasitas bandwith setiap pengguna sesuai dengan 
kebutuhan atau permintaan pada Madrasah Aliyah Al-Azhaar Ummu Suwanah.

Adapun tujuan dilakukannya penelitian ini adalah: 1) Membuat sebuah jaringan hotspot mikrotik dengan sistem login untuk para pengguna baik, guru, staff maupun siswa di Madrasah Aliyah Al-Azhaar Ummu Suwanah, 2) Membuat sebuah sistem manajemen user pada jaringan hotspot sehingga administrator jaringan dapat mengontrol dan memonitoring pengguna hotspot, 3) Konfigurasi manajemen bandwidth untuk pengguna hotspot mikrotik.

\section{TINJAUAN PUSTAKA}

\section{A. Pengertian Jaringan Komputer}

Jaringan komputer adalah sekelompok komputer otonom yang saling menggunakan protokol komunikasi melalui media komunikasi sehingga dapat berbagi data, informasi, program aplikasi dan perangkat seperti printer, scanner, CD Driver ataupun hardisk, serta memungkinkan untuk saling berkomunikasi secara elektronik [3].

\section{B. Pengertian Internet Service Provider (ISP)}

Internet Service Provider (ISP) merupakan perusahaan jasa yang menyediakan jasa layanan koneksi ke internet. Melalui ISP ini kita dapat berhubungan dengan komputer-komputer diseluruh dunia. Berdasarkan keberadaannya ISP terbagi menjadi ISP lokal (tingkat regional). ISP nasional (tingkat negara) dan ISP internasional dikenal sebagai (mainstream ISP). Macam-macam provider yang sering kita dengar yaitu: Firstmedia, Indihome, Indosat Ouredoo GIG dan MNC Play Media [4].

\section{Winbox}

Winbox adalah utility yang digunakan untuk konektivitas dan konfigurasi mikrotik menggunakan MAC address atau protokol IP. Dengan winbox kita dapat melakukan konfigurasi Mikrotik RouterOS menggunakan GUI dengan cepat dan sederhana. Winbox dibuat menggunakan win32 binary tapi dapat dijalankan pada Linux, Mac OSX dengan menggunakan wine. Mengkonfigurasi mikrotik ini lebih banyak digunakan karena selain penggunaannya yang mudah anda juga tidak harus menghapal perintah-perintah console [2].

\section{Pengertian RADIUS Server}

Remote Access Dial In User Service (RADIUS) server merupakan protokol connectionless berbasis UDP yang tidak menggunakan koneksi langsung dan ditandai dengan field UDP yang menggunakan port. RADIUS server sendiri merupakan suatu mekanisme akses kontrol yang mengecek dan mengautentifikasi (authentication) user atau pengguna berdasarkan pada mekanisme autentikasi dengan menggunakan metode challenge/response [1].

\section{E. Pengertian Usermanager}

Usermanager adalah aplikasi server RADIUS yang dapat digunakan untuk managemen diantaranya pengguna Hotspot, pengguna PPP (PPtP/PPPoE), pengguna DHCP, pengguna nirkabel dan pengguna Router OS [1].

\section{F. Hotspot}

Banyak orang awam yang menyebut jika terdapat akses internet yang disebarkan pada (cafe, mall dan sebagainya) itu adalah layanan Hotspot. "Sedangkan sebenarnya Hotspot pada Mikrotik adalah sebuah system untuk memberikan filtur autentikasi pada user yang akan mengakses suatu jaringan. Jadi untuk bisa mengakses ke jaringan, client diharuskan memasukkan username dan password pada loginpage yang tersedia. "(Pujo Dewobroto, Filtur-filtur Hotspot Mikrotik, 2017) Filtur Hotspot pada Mikrotik bisa juga diakses melalui jaringan LAN dengan IP DHCP dan dapat kita manage menggunakan username dan password serta kita juga dapat melakukan pembatasan Limited Time (Time Base) dan Qouta base (Kouta kapasitas bandwidth). Konfigurasi ini sangat cocok untuk penggunaan layanan Hotspot Public seperti Hotel, Cafe dan Restoran [4].

Hotspot merupakan filtur gabungan dari berbagai service yang ada di Mikrotik, antara lain:

1. DHCP server, digunakan untuk memberikan layanan IP otomatis ke user.

2. Firewall NAT, untuk mentranslasi IP user ke IP yang bisa dikenali ke internet.

3. Firewall filter, untuk mem-block user yang belum melakukan login.

4. Proxy, untuk memberikan tampilan halaman login dan sebagainya [4].

\section{METODE PENELITIAN}

Metode penelitian yang digunakan dalam penelitian ini adalah sebagai berikut :

A. Analisa Penelitian

Analisa penelitian data yang dilakukan pada penelitian ini meliputi :

1. Analisa Kebutuhan

Tahap dari pembuatan jaringan komputer ini adalah penulis pertama melakukan pencarian alat-alat dan komponen-komponen yang dibutuhkan mulai dari pengertian sampai fungsinya. Kemudian setelah melakukan pencarian yaitu pembelian alat, komponen dan terakhir pengujian untuk jaringan komputer.

2. Desain

Dari penelitian yang didapatkan sebelumnya, tahap desain ini akan membuat desain topologi jaringan komputer berupa jaringan wireless untuk hotspot yang disesuaikan dengan kondisi di Madrasah Aliyah Al-Azhaar Ummu Suwanah.

3. Testing

Testing adalah tahap untuk melakukan implementasi pada rancangan hotspot mikrotik yang sudah dibuat, apakah sudah sesuai dan bisa digunakan untuk melakukan pengujian.

4. Implementasi

Pengimplementasian jaringan komputer ini diterapkan ke dalam topologi yang telah dirancang sedemikian rupa untuk menyesuaikan jaringan komputer yang ada di Madrasah Aliyah Al-Azhaar Ummu Suwanah. 
B. Metode Pengumpulan Data

Metode pengumpulan data yang dilakukan pada penelitian ini meliputi :

1. Observasi

Melalui metode ini penulis melakukan observasi langsung pada Madrasah Aliyah Al-Azhaar Ummu Suwanah, observasi dilakukan guna melihat langsung keadaan Madrasah Aliyah terutama ruang staff, guru dan lab siswa. Setelah dari pengamatan yang dilakukan, data dikumpulkan sebagai sumber informasi.

2. Wawancara

Penelitian ini dilakukan langsung dengan cara tanya jawab dengan Ustadz Dr. Amirudin Hamzah, MA yang ada di Madrasah Aliyah Al-Azhaar Ummu Suwanah. Penelitian ini dilakukan untuk memperoleh data yang lebih detail.

3. Studi Pustaka

Agar data sesuai dengan teori maka penulis mengumpulkan berbagai sumber-sumber referensi baik berupa buku, artikel, jurnal dan sumber-sumber lainnya sebagai acuan dalam implementasi jaringan komputer berbasis RADIUS server.

\section{IV.PEMBAHASAN DAN HASIL}

A. Manajemen Jaringan Usulan

1. Topologi Jaringan

Topologi yang diusulkan dalam penelitian ini dapat digambarkan sebagai berikut.

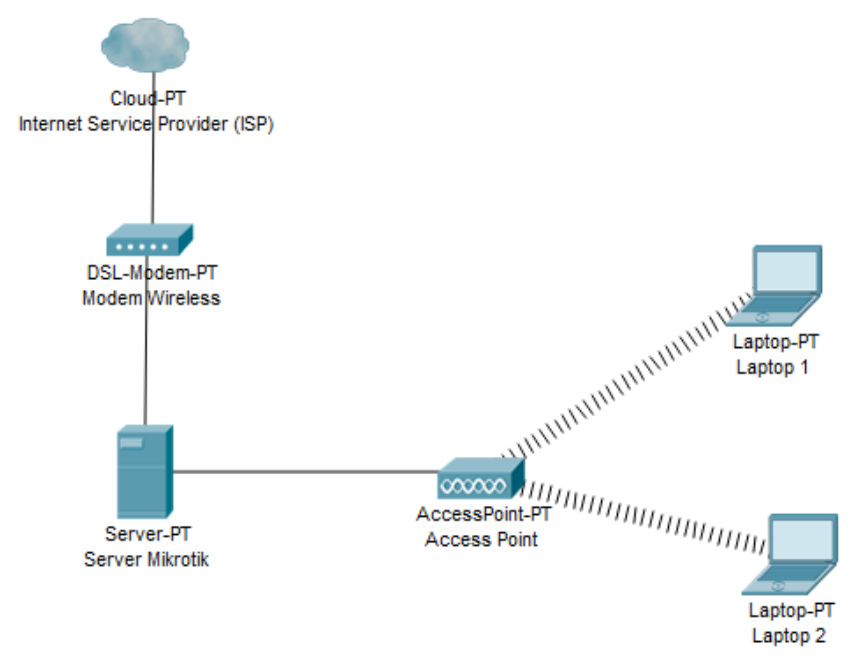

Sumber: Hasil Penelitian

Gbr.1. Rancangan Usulan Topologi Jaringan Hotspot

Topologi jaringan komputer yang akan digunakan penulis terhadap penelitian yang telah dilakukan yaitu topologi star dengan konsep wireless, dimana konsep dari topologi star ini ialah topologi yang umum digunakan untuk hotspot. Hotspot menjadi penghubung untuk akses internet bagi si pengguna.

Penulis merancang topologi star ini karena menyesuaikan dengan keadaan yang ada di Madrasah Aliyah Al-Azhaar Ummu Suwanah dan memudahkan guru, staff dan siswa masuk ke jaringan hotspot dengan wireless untuk akses internet.

Topologi star diatas diusulkan karena beberapa hal diantaranya:

1. Adanya server guna untuk mengontrol dan memonitoring segala keperluan jaringan, terutama dalam jaringan hotspot.

2. Memudahkan dalam penambahan perangkat jaringan komputer lainnya untuk memperluas jaringan hotspot dan memperbanyak user hotspot mikrotik.

3. Memudahkan user dalam akses internet tanpa harus menggunakan kabel.

4. Jika ada kesalahan seperti jaringan terputus, maka dengan mudah untuk menyelesaikannya.

5. Keamanan jaringan dikatakan cukup baik dan terkendali karena adanya server dengan tidak sembarangan user bisa masuk ke jaringan hotspot tanpa ada username dan password di databsae usermanager mikrotik.

\section{Skema Jaringan}

Skema jaringan yang telah diusulkan penulis terdiri dari beberapa komponen jaringan utama yang saling berhubungan dengan membentuk suatu jaringan Wireless Local Area Network (WLAN), yaitu akses internet dari Internet Service Provider (ISP) melalui modem wireless. PC router mikrotik yang memiliki dua buan LAN card dan WLAN card. PC router mikrotik ini berfungsi sebagai server untuk mengatur segala keperluan jaringan hotspot. Kemudian access point perangkat untuk membagi koneksi jaringan ke perangkat jaringan yang lain berupa wireless yaitu laptop atau PC client. Dimana access point yang sudah dirancang merupakan penghubung antar user dengan jaringan hotspot.

\section{Mekanisme Otentikasi User}

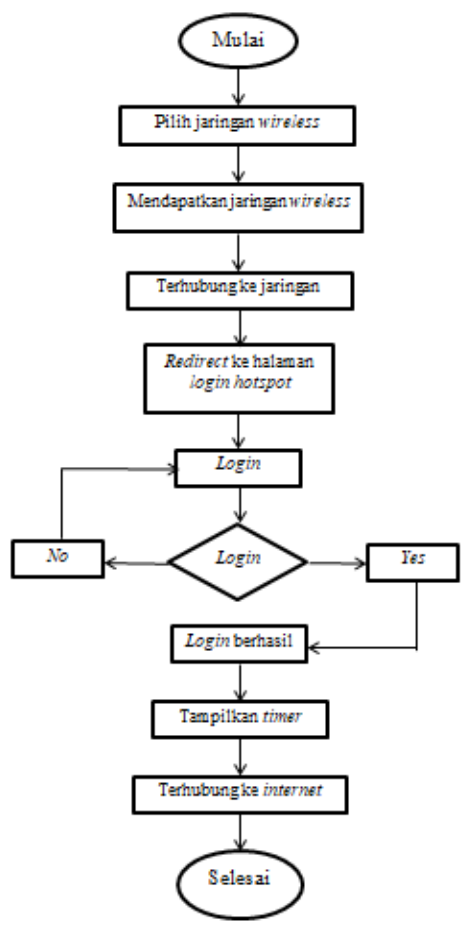

Sumber: Hasil Penelitian

Gbr.2. Flowchart Sistem Jaringan Hotspot 
Cara kerja otentikasi jaringan komputer hotspot ini adalah pertama setiap user yang masuk kedalam hotspot lewat wireless dan mencoba untuk akses internet, semuanya akan redirect ke halaman website untuk login username dan password yang dibuat oleh usermanager mikrotik. Ketika username dan password dimasukkan maka usermanager mikrotik akan menanyakan ke penyimpanan usermanager apakah ada username dan password yang dimasukkan oleh si user bersangkutan. Kemudian mencocokkan username dan password yang dimasukkan melalui penyimpanan usermanager yang dibuat di RADIUS server. Jika ada, si RADIUS server akan melaporkan kepada usermanager untuk memberikan izin sehingga user bisa akses atau browsing internet, dan jika tidak ada, maka RADIUS server akan melaporkan ke usermanager bahwa username dan password yang dimasukkan tidak ada, usermanager mikrotik tidak akan membuka akses atau mendapatkan layanan internet dan akan meminta login ulang dan begitu seterusnya.

\section{B. Rancangan Jaringan}

Langkah-langkah pengerjaan rancangan jaringan hotspot mikrotik adalah:

1. Konfigurasi Server Mikrotik

a) Setting winbox mikrotik

Winbox mikrotik berfungsi untuk konektivitasi dan konfigurasi mikrotik. Untuk masuk ke winbox mikrotik dengan pilih MAC address winbox dan pilih connect.

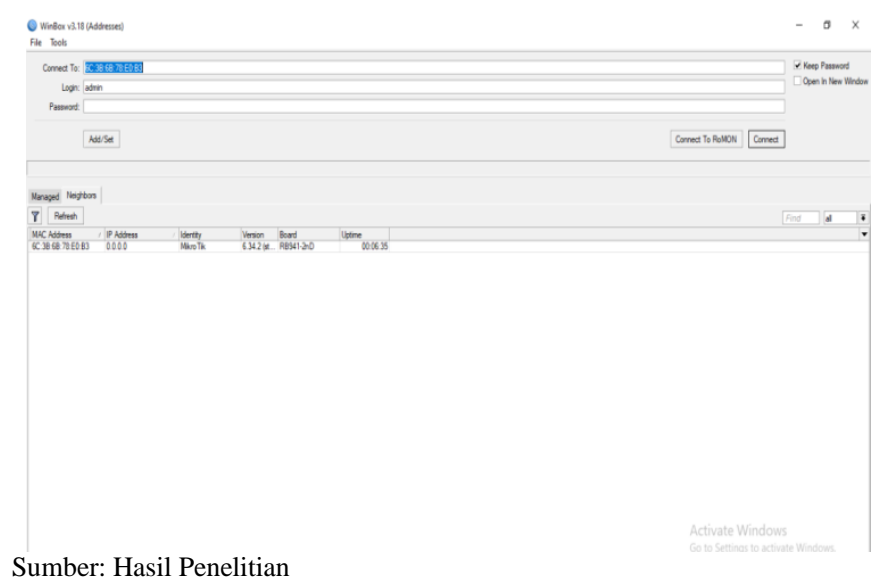

Sumber: Hasil Penelitian

Gbr.3. Setting Winbox Mikrotik

b) Konfigurasi IP DHCP client

DHCP client berfungsi untuk mendapatkan akses internet dari Internet Service Provider (ISP) dengan IP public menjadi IP static local secara otomatis. Untuk setting DHCP client dengan memilih pada simbol tambah pada DHCP client dan mengaktifkan pada interface yang terhubung ke mikrotik.

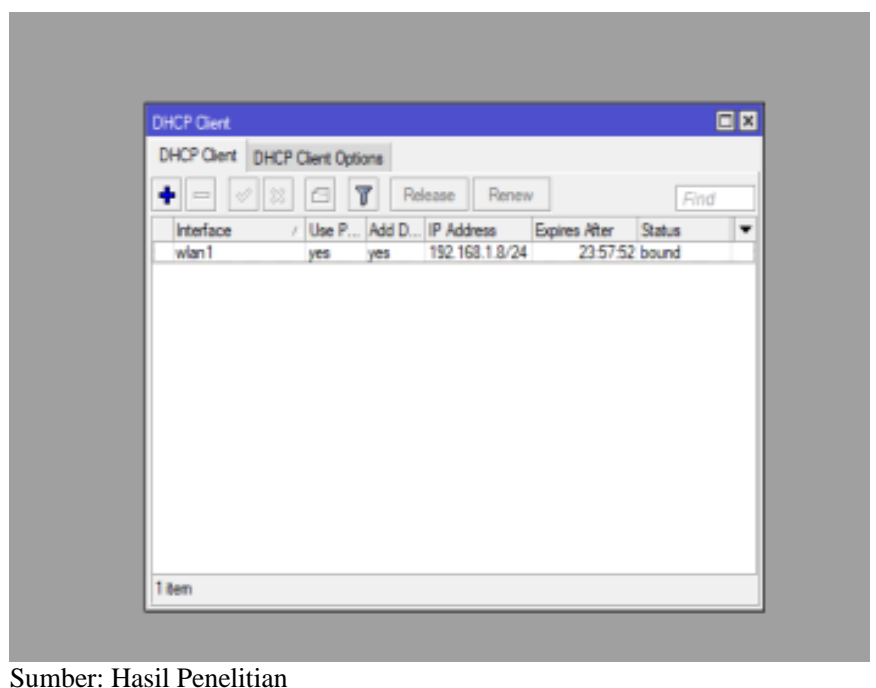

Sumber: Hasil Penelitian

Gbr.4. Konfigurasi IP DHCP Client

c) Konfigurasi IP address untuk LAN mikrotik

Konfigurasi IP address untuk LAN mikrotik berfungsi sebagai server mikrotik untuk membangun sebuah jaringan lokal untuk akses internet dan mengatur jaringan hotspot serta keperluan lainnya. Caranya pilh pada simbol tambah pada address kemudian mengisi IP address 192.168.50.50/24, network 192.168.50.0 dan interface ether 2 yang terhubung ke mikrotik. Untuk mengisi IP address ini tidak ditentukan berapa IP address-nya, tetapi sesuai dengan kebutuhan saja.

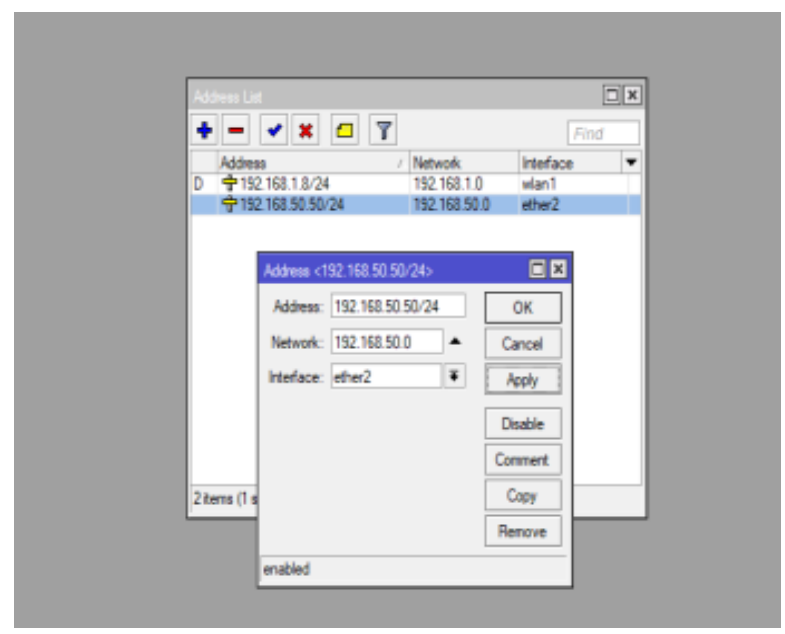

Sumber: Hasil Penelitian

Gbr.5. Konfigurasi IP Address Untuk LAN

d) Konfigurasi IP DHCP server setup untuk LAN

Dynamic Host Configuration Protocol (DHCP) server bekerja sebagai memberikan response terhadap request yang dikirimkan oleh DHCP client secara otomatis. Konfigurasi DHCP server dengan memilih DHCP setup dan pilih next setiap langkah-langkah pada DHCP setup hingga sukses tanpa ada diubah apapun. 


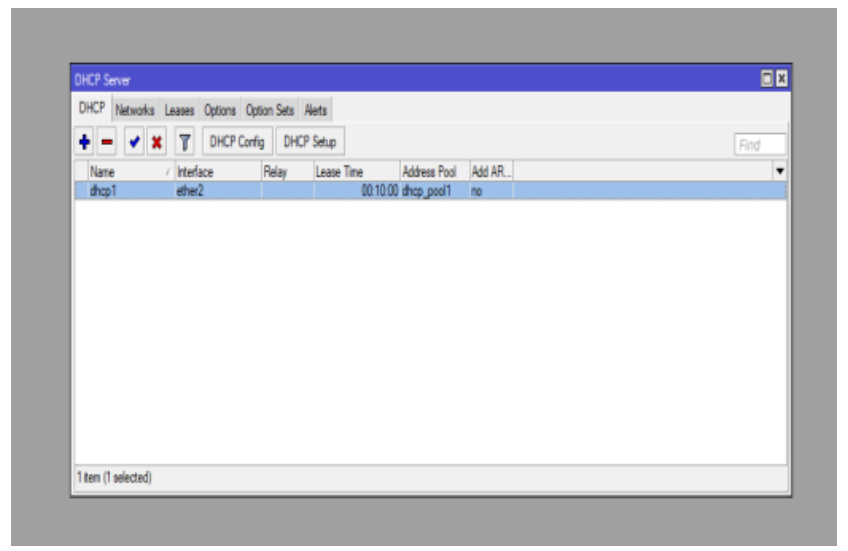

Sumber: Hasil Penelitian

Gbr.6. Konfigurasi IP DHCP Server Setup

e) Mengatur DNS

Domain Name System (DNS) server merupakan sebuah cara untuk mengubah URL website menjadi IP address. Untuk mengatur DNS server yaitu memilih pada simbol tambah pada DHCP kemudian mengisi pada server 8.8.8.8 dan 8.8.4.4 dan mencentangkan pada allow remote request. Pengisian pada server dan pemberian centang pada allow remote request untuk alamat DNS server bagi client.

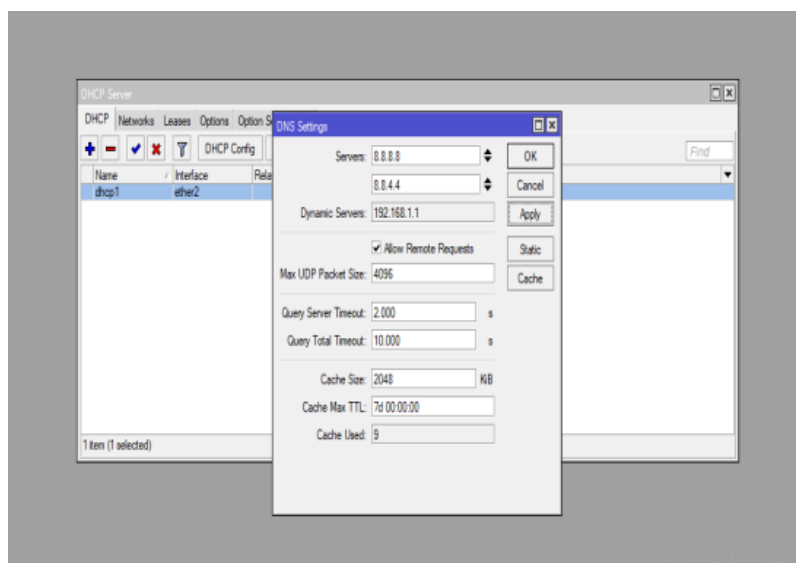

Sumber: Hasil Penelitian

Gbr.7. Konfigurasi DNS Server

f) Setting firewall

Firewall ini berfungsi untuk memeriksa dan menentukan paket data yang dapat keluar atau masuk ke jaringan untuk sebuah keamanan jaringan itu sendiri. Mengatur firewall dengan memilih NAT, pilih pada tombol NAT, pilih general dengan mengisi srcnat pada chain dan pilih masquerade pada action.

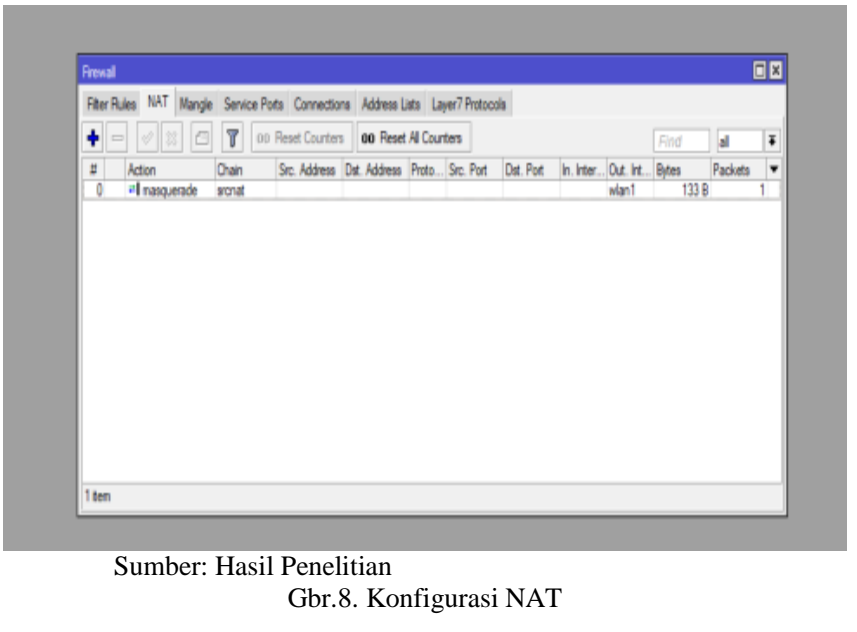

g) Konfigurasi IP address untuk hotspot

Konfigurasi IP address untuk hotspot mikrotik berfungsi sebagai alamat web hotspot untuk akses internet dengan memilih pada tombol address list kemudian mengisi IP address 192.168.100.100/24, network 192.168.100.0 dan interface ether 3 yang terhubung ke mikrotik. Untuk mengisi IP address ini tidak ditentukan berapa IP addressnya, tetapi sesuai dengan kebutuhan saja dan harus berbeda dengan IP address LAN.

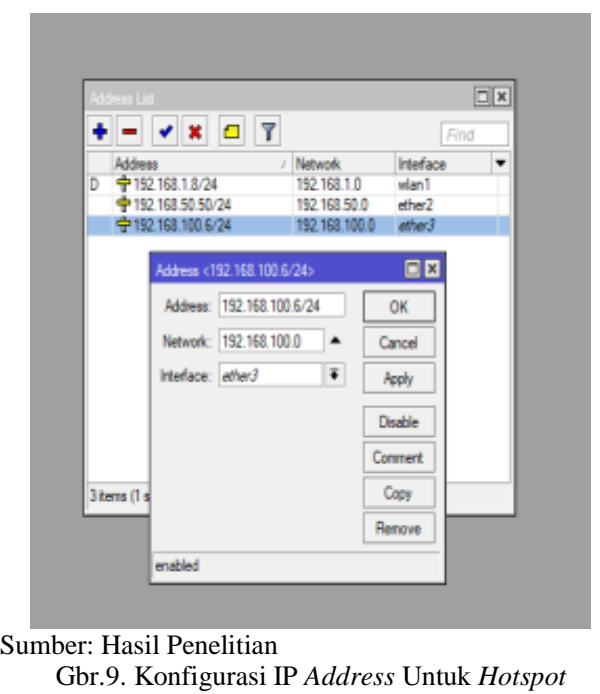

h) Konfigurasi hotspot

Hotspot adalah dimana sebuah client dapat terhubung ke jaringan internet tanpa menggunakan kabel seperti laptop, Hp dengan jangkauan radius beberapa ratus meter. Konfigurasi hotspot dengan memilih dan mengatur hotspot setup dengan mengikuti langkah-langkah dengan tekan next kemudian mengisi DNS name www.alazhar.com (sesuai nama kebutuhan). DNS name ini sebagai alamat DNS untuk client. 


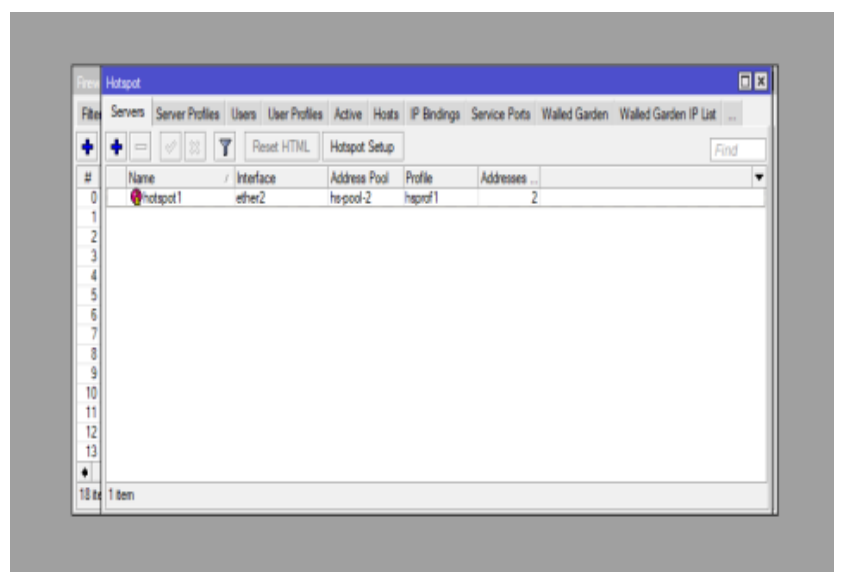

Sumber: Hasil Penelitian

Gbr.10. Setting Hotspot

i) Mengaktifkan RADIUS server

RADIUS server merupakan protokol jaringan yang menjalankan servis manajemen ototentikasi, otorisasi dan akuntasi secara terpusat untuk user. Setting RADIUS server untuk hotspot dengan memilih servers profiles yang sudah dibuat sebelumnya kemudian beri centang pada Use RADIUS di RADIUS.

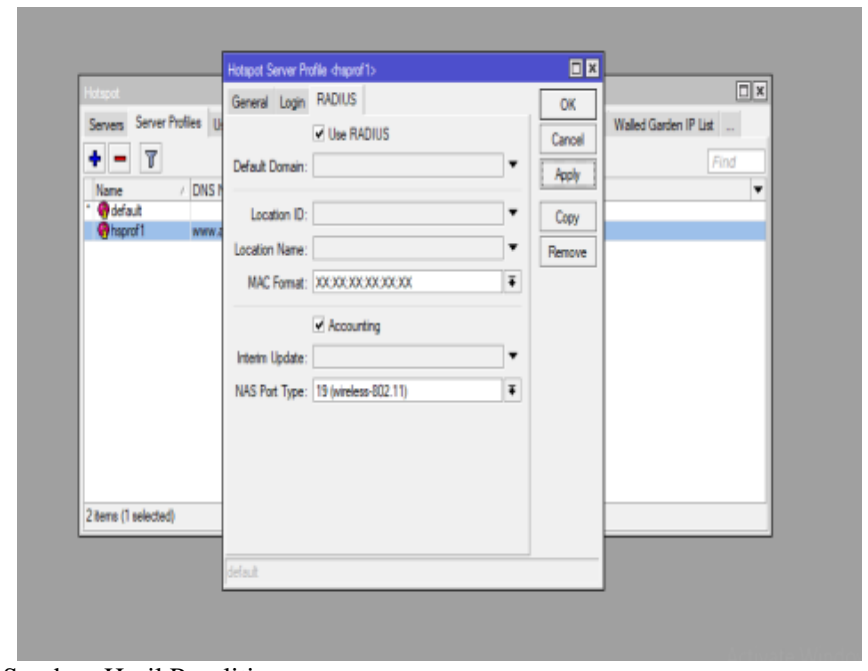

Sumber: Hasil Penelitian

Gbr.11. Mengaktifkan RADIUS Server

j) Konfigurasi RADIUS

Konfigurasi RADIUS dengan memilih pada tombol tambah kemudian mengatur general dan mencentangkan pada hotspot, isi pada address yaitu 127.0.0.1 (karena hanya 1 mikrotik) dan beri password admin (sesuai kebutuhan) pada secret.

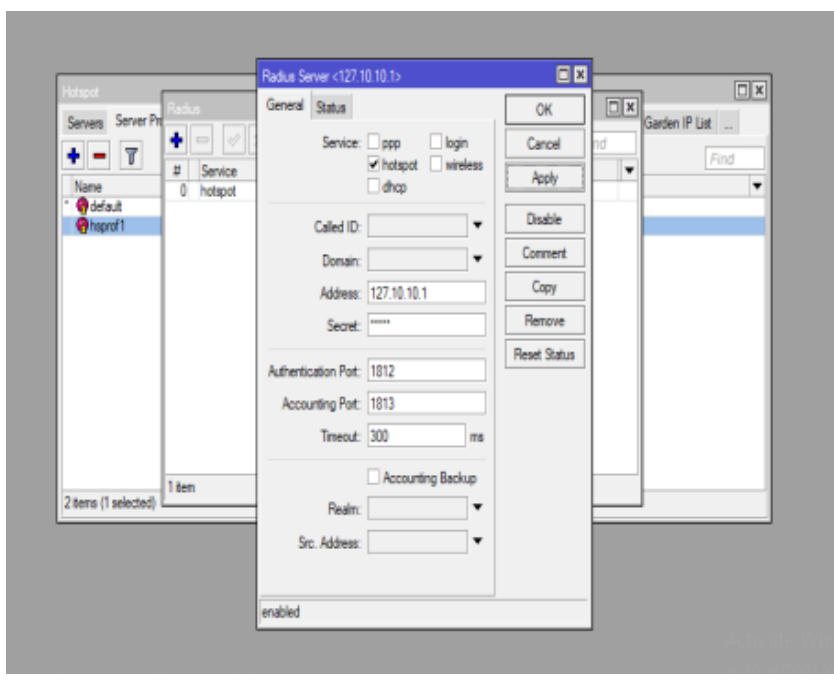

Sumber: Hasil Penelitian

Gbr.12. Konfigurasi RADIUS

k) Konfigurasi usermanager

Usermanager berfungsi untuk memudahkan ketika kita ingin membuat layanan jaringan internet yang didistribusikan secara luas, seperti membuat hotspot untuk kafe, mall dan membuat voucher internet. Konfigurasi usermanager dengan masuk web browser (google chrome) dan masukkan IP address 192.168.100.100/userman kemudian login dengan mengisi admin tanpa mengisi password. IP address usermanager ini terdapat dari pengaturan hotspot yang ada di mikrotik sebelumnya.

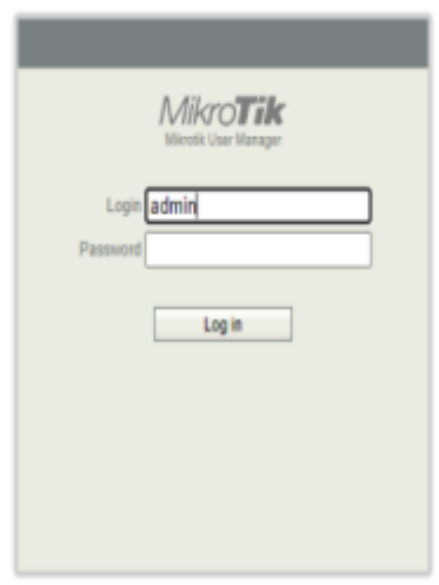

Sumber: Hasil Penelitian

Gbr.13. Halaman Userman

1) Setting routers usermanager

Setting routers usermanager dengan mengisi nama alazharummusuwanah (sesuai kebutuhan/permintaan) kemudian isi IP address 127.0.0.1 (karena menggunakan 1 mikrotik) dan isi password admin di shared secret (sesuaikan dengan pengaturan sebelumnya yang ada di mikrotik). 


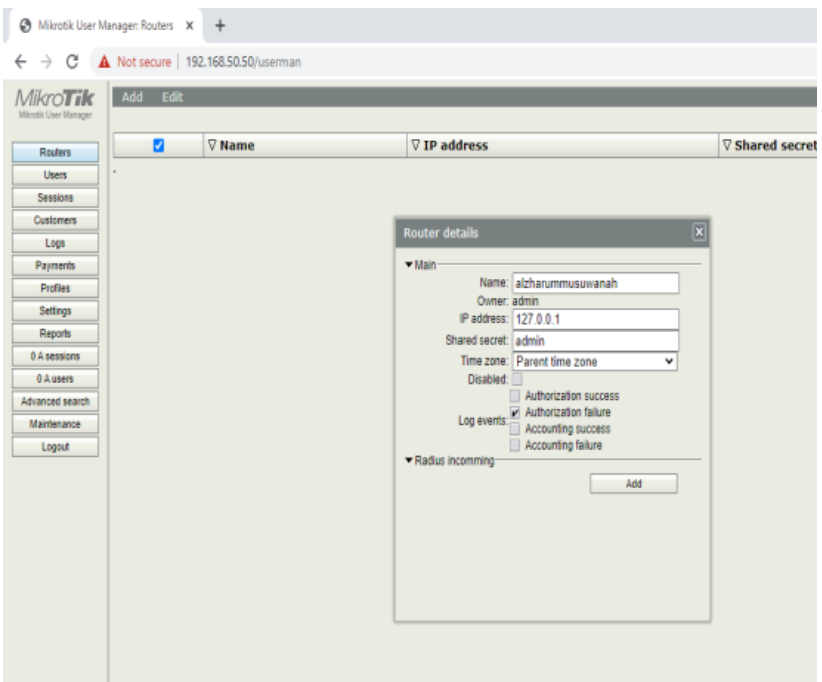

Sumber: Hasil Penelitian

Gbr.14. Konfigurasi Routers Usermanager

m) Manajemen bandwidth (paket internet) untuk user

Manajemen bandwidth ini berfungsi untuk mengatur kecepatan jaringan internet untuk masing-masing client. Setting bandwidth dengan masuk ke tabs profiles dan pilih profiles dan limitations untuk mengatur bandwidth (paket internet) sesuai keperluan untuk setiap user.
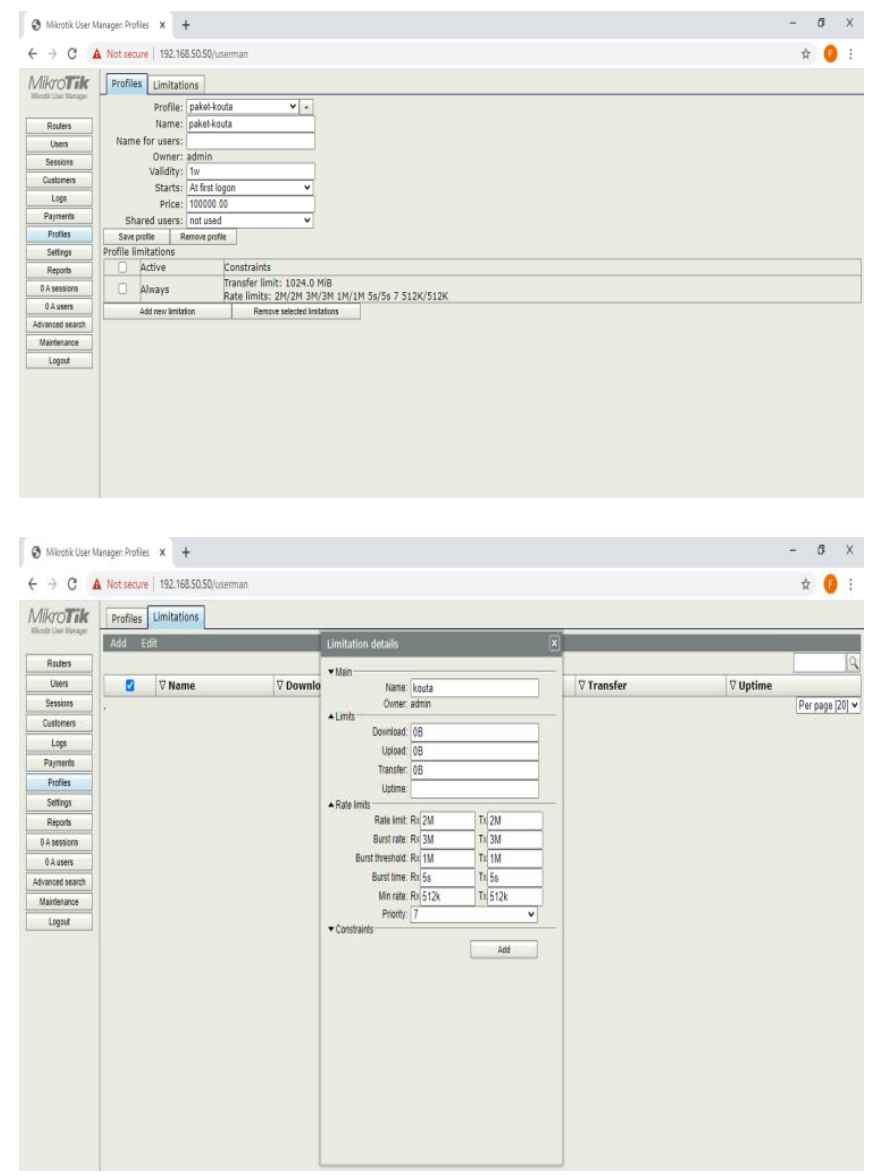

Sumber: Hasil Penelitian

Gbr.15. Setting Bandwidth n) Konfigurasi user untuk mendapatkan akses internet Konfigurasi user merupakan cara pengelolahan user agar mendapatkan username dan password untuk akses internet saat masuk ke jaringan. Caranya dengan masuk ke tabs users dan mengisi username dan password sesuai dengan keinginan kemudian memilih paket yang sudah dibuat sebelumnya. Pembuatan user ini sesuai dengan banyak pengguna yang dibutuhkan.

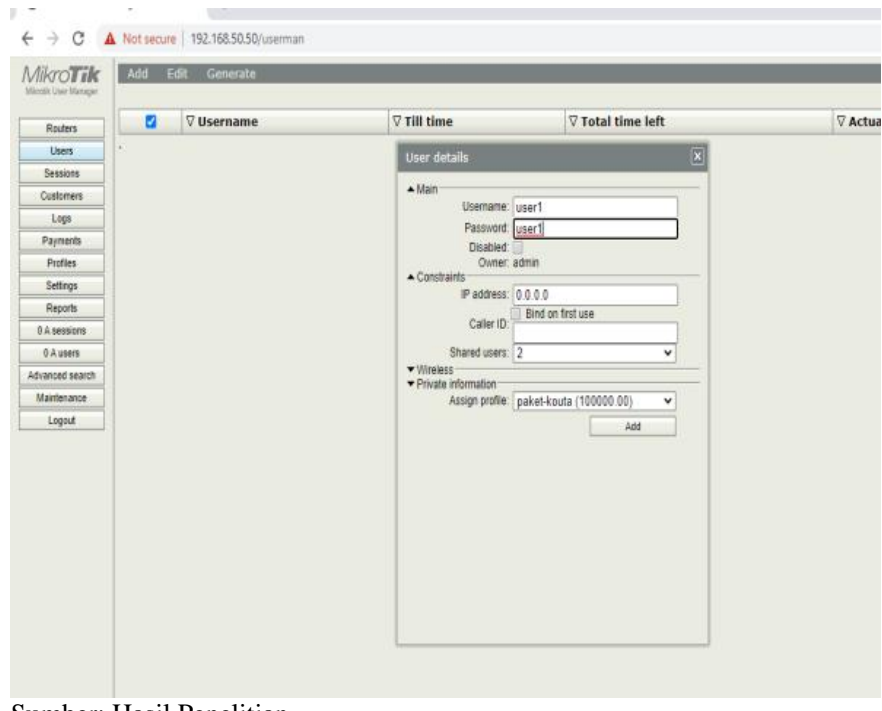

Sumber: Hasil Penelitian

Gbr.16. Konfigurasi User

2. Konfigurasi access point

a) Masuk ke web browser

Masuk ke web browser dengan mengisi link access point http://tplinkwifi.net kemudian masuk dengan mengisi username admin dan password admin (dari access point) dan pilih $\log$ in.

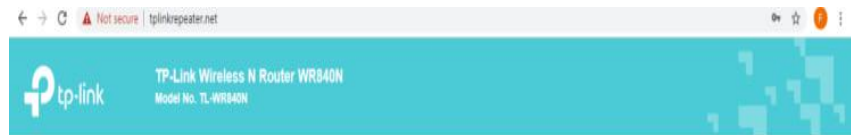

Sumber: Hasil Penelitian

Gbr.17. Halaman Access Point

b) Konfigurasi wireless

Konfigurasi wireless dengan masuk tabs wireless dan mengatur atau mengubah SSID (nama WiFi) menjadi alazhaarummusuwanah (sesuai permintaan) dan pilih save. 


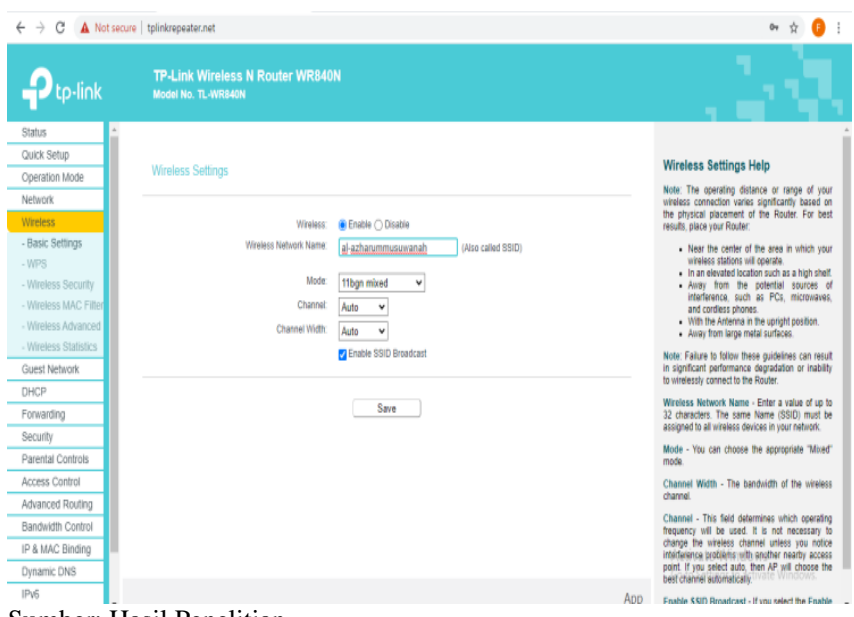

Sumber: Hasil Penelitian

Gbr.18. Konfigurasi Wireless

c) Mengubah password pada wireless (hotspot)

Mengubah password dengan memilih wireless security dan mengatur password WiFi sesuai kebutuhan dan pilih save.

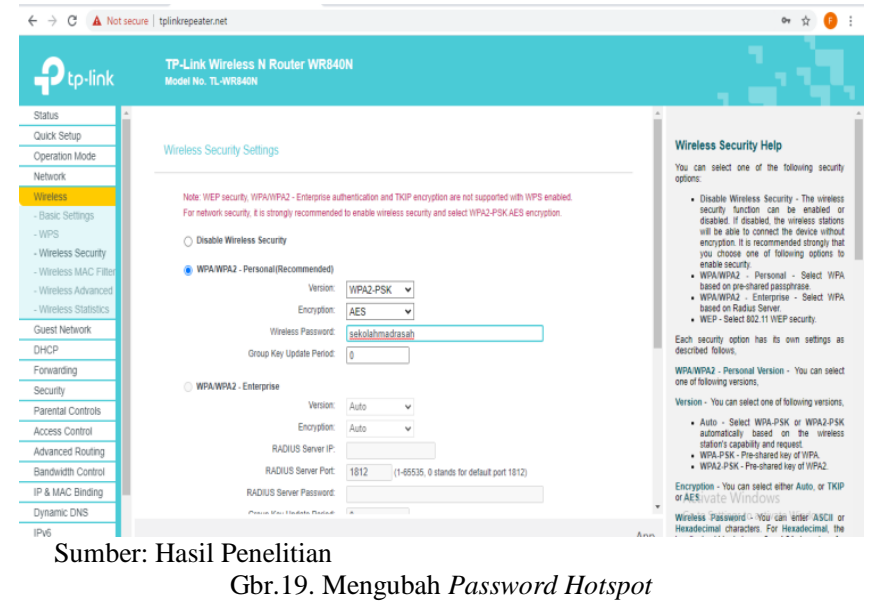

d) Setting DHCP server wireless

Setting DHCP server wireless dengan masuk ke DHCP kemudian pilih disable pada DHCP server selanjutnya save.

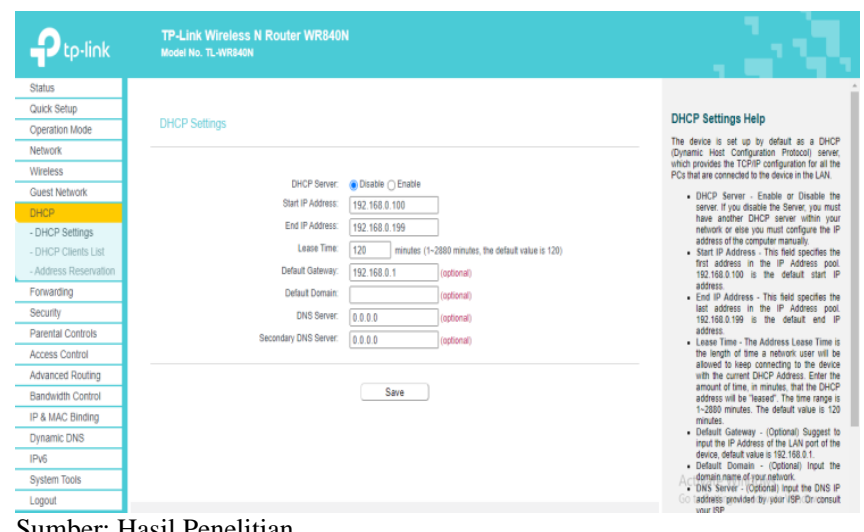

Sumber: Hasil Penelitian

Gbr.20. Setting DHCP Server Wireless e) Setting IP address LAN access point pada network wireless

Setting IP address untuk access point pada bagian networks dan pilih LAN kemudian mengisi IP address 192.168.100.2 (sesuai kebutuhan) dan subnetmask 255.255.255.0 selanjutnya pilih save.

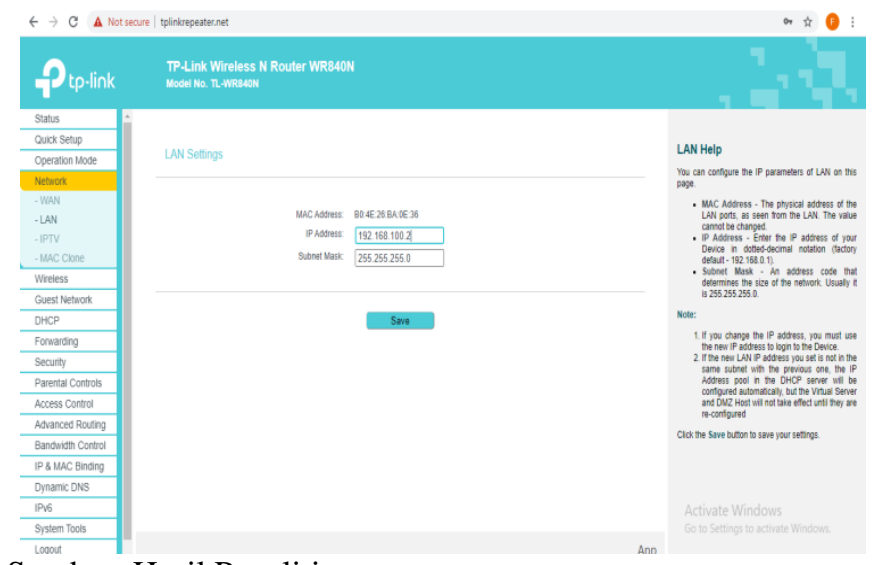

Sumber: Hasil Penelitian

Gbr.21. Setting IP Address LAN Pada Network Wireless

3. Percobaan user dalam pemanfaatan internet dengan hotspot

a. Connect WiFi dengan nama Madrasah alazhaarummusuwanah yang sudah dibuat sebelumnya.

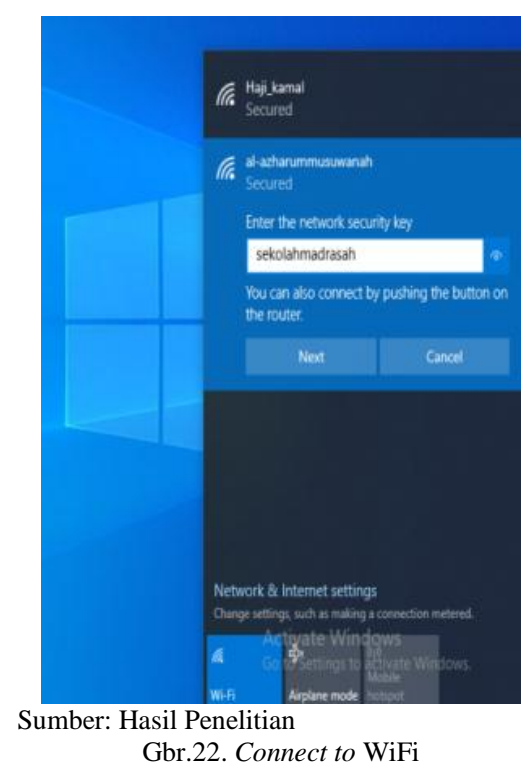

b. Redirect ke web browser dengan DNS www.alazhar.com kemudian megisi username dan pssword si user selanjutnya pilih ok. 


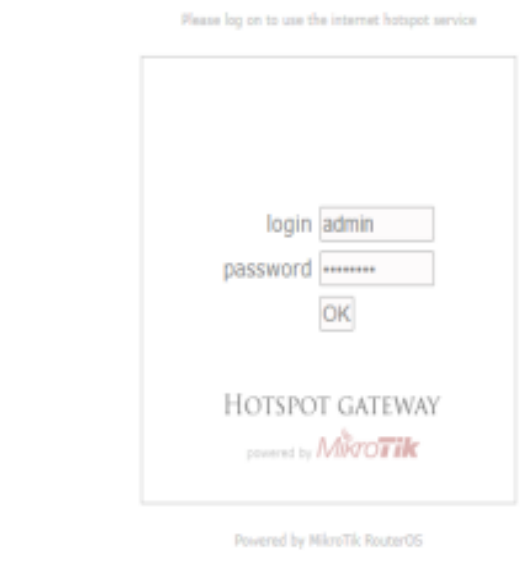

Sumber: Hasil Penelitian

Gbr.23. Halaman Login Hotspot

c. Masuk dan mendapatkan akses internet.

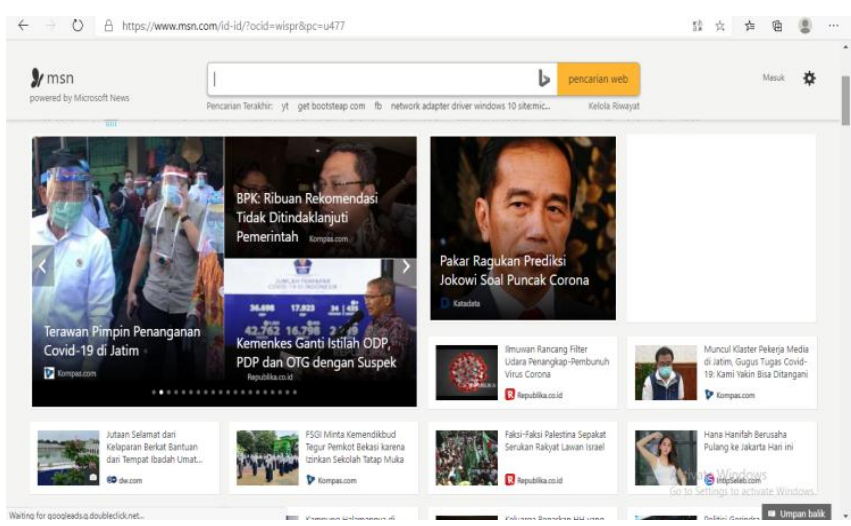

Sumber: Hasil Penelitian

Gbr.24. Halaman Akses Internet

\section{Pengujian Jaringan}

Dalam membangun sebuah jaringan komputer tentu perlu adanya pengujian terhadap jaringan tersebut untuk memastikan berjalan dengan apa yang sudah direncanakan.

1. Pengujian Jaringan Awal

Penulis melakukan test jaringan menggunakan speedtest (www.speedtest.net) di browser sebelum diterapkan hotspot mikrotik berbasis RADIUS server dengan usermanager, adapun bandwidth yang didapatkan pada gambar berikut.

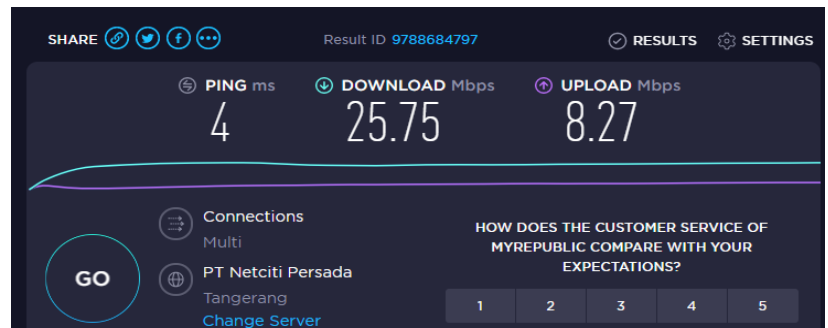

Sumber: Hasil Penelitian

Gbr.25. Pengujian Jaringan Awal
Alokasi bandwidth akses internet yang ada di Madrasah Aliyah Al-Azhaar Ummu Suwanah sebesar 4 Mbps, untuk kecepatan download 25,75 (26) Mbps dan upload 8,27 (9) Mbps. Kecepatan bandwidth yang dimiliki Madrasah Aliyah Al-Azhaar Ummu Suwanah ini cukup tinggi karena tidak adanya manajemen bandwidth untuk setiap pengguna akses internet. Tetapi lemahnya atau keterlambatan dalam akses internet saat banyak pengguna masuk pada jaringan yang sama.

\section{Pengujian Jaringan Akhir}

Penulis melakukan pengujian jaringan akhir dalam menerapkan jaringan hotspot mikrotik dengan DNS name www.alazhar.com di browser untuk login user dan menggunakan www.speedtest.net untuk mengetahui kecepatan bandwidth jaringan, maka didapatkan hasil pada gambar berikut.

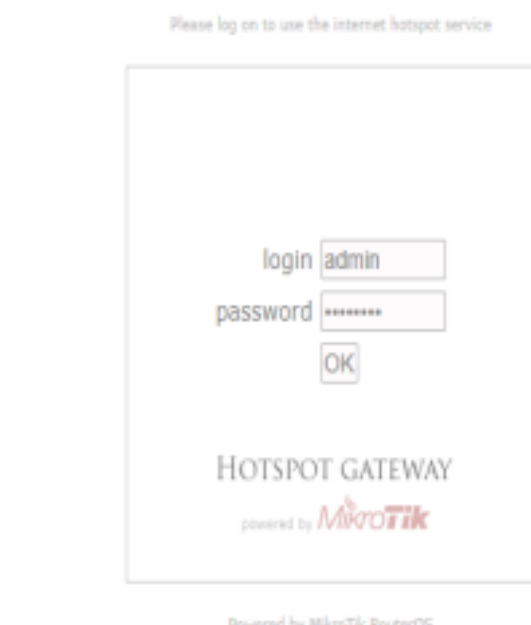

Sumber: Hasil Penelitian

Gbr.26. Pengujian Jaringan Akhir Halaman Login User

Halaman login user hotspot diatas membuktikan bahwa pengguna bisa masuk ke jaringan untuk akses internet dengan adanya username dan password yang ada di alokasi atau database usermanager mikrotik. Dengan demikian, keamanan jaringan dapat tertutupi dari pengguna yang tak dikenal saat untuk masuk ke jaringan.

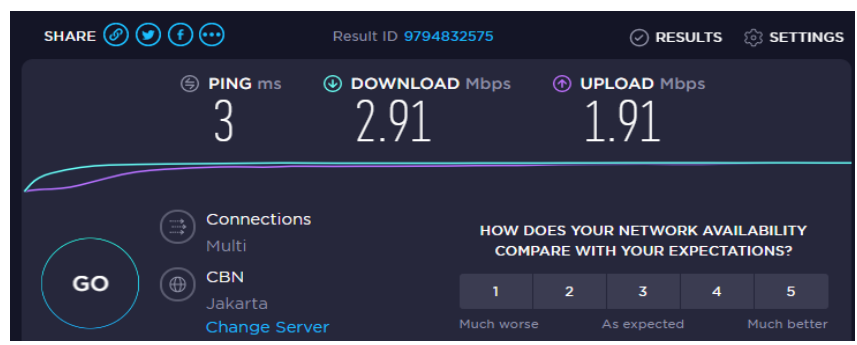

Sumber: Hasil Penelitian

Gbr.27. Pengujian Jaringan Akhir Bandwidth User

Dalam perancangan jaringan hotspot berbasis RADIUS server menggunakan usermanager pada Madrasah Aliyah Al- 
Azhaar Ummu Suwanah, bahwa bandwidth yang didapat tidak melonjak tinggi yaitu untuk download 3 Mbps dan upload 2 Mbps. Bandwidth tersebut hasil dari pengujian dari 1 (satu) pengguna jaringan hotspot yang sudah diatur dengan usermanager oleh administrator jaringan sesuai dengan permintaan.

\section{KESIMPULAN}

Berdasarkan hasil pengamatan dan analisa penulis mengenai jaringan komputer berbasis RADIUS sever pada Madrasah Aliyah Al-Azhaar Ummu Suwanah dapat disimpulkan bahwa dengan menerapkan RADIUS server pada jaringan hotspot dapat meningkatkan penggunaan internet, memudahkan manajemen bandwidth pada jaringan hotspot tersebut dan keamanan jaringan yang aman karena tidak sembarangan user masuk tanpa ada penggunaan yang terdaftar di penyimpanan usermanager mikrotik, serta dapat memudahkan administrator jaringan untuk melakukan segmentasi jaringan antar divisi pada lingkup area jaringan hotspot.

\section{UCAPAN TERIMA KASIH}

Penulis mengucapkan terima kasih kepada tim jurnal yang telah memberikan kesempatan pada penulis untuk menerbitkan penelitian ini pada jurnal teknik informatika (JTI) STMIK Antar Bangsa.

\section{REFERENSI}

[1] T. W. E. Vivanda and I. A. Susanti, "Rancang Bangun Sistem Jaringan Hotspot Berbasis Manajemen User Dengan Menggunakan Userman dan Radius Server Pada Mikrotik Routerboard di SMK Negeri 1 Kemlagi," TECHOSCIENZA, vol. III, pp. 246-260, 2019.

[2] A. Feby and T. Akbar, "Perancangan Sistem Monitoring Keamanan Jaringan Jarak Jauh Menggunakan Mikrotik Operational System Melalui Virtual Private Network," Surya Energy, vol. II, pp. 135-139, 2017.

[3] W. F. Pattipeilohy, "Analisis dan Perancangan User Manager pada Mikrotik Router dengan Sistem Pembelian Kredit Voucher," SISFOKOM, vol. V, pp. 64-69, 2016.

[4] T. S. Fitria and A. Prihanto, "Implementasi Generate Voucher Hotspot Dengan Batasan Waktu (Time Based) Dan Kuota (Quota Based) Menggunakan User Manager Di Mikrotik," Manajemen Infomatika, vol. VIII, pp. 18-24, 2018.

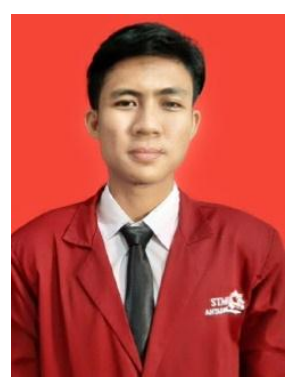

Fadlan Abdillah Hasibuan. Lahir di Belawan pada Tanggal 13 Juni 1998. Tahun 2020 lulus dari Program Strata Satu (S1) Jurusan Teknik Informatika di STMIK Antar Bangsa. Saat ini bekerja tenaga pendidik dan operator sekolah di SMPQ/SMAQ PPTQ Imam An Nawawi, Sekupang, Batam.

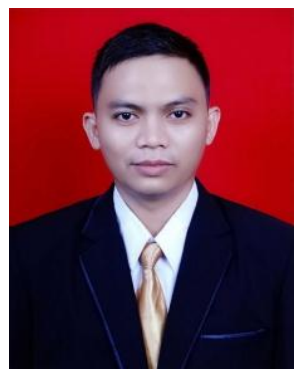

Subhiyanto, lahir di Brebes pada tanggal 10 Maret 1984. Tahun 2012 Lulus Sarjana Komputer Jurusan Teknik Informatika di STMIK Nusa Mandiri. Tahun 2020 lulus program pasca sarjana Ilmu Komputer dengan konsentrasi Rekayasa Komputasi Terapan di Universitas Budi Luhur. Saat ini aktif mengajar sebagai dosen tetap dan sebagai Kepla Biro Teknologi Informasi di STMIK Bangsa. 